\title{
Ensino do Direito na UFPR: Voto à Esperança ${ }^{1}$
}

\author{
Lacinta Otelson de Ollivanda Coutinho
}

Mestre (UFPR) e Doutor (Università degli Studi di Roma "La Sapienza"), Coordenador eleito do Programa de Pós-graduação em Direito da UFPR, Professor de Direito Processual Penal na UFPR (Graduação e Pós-graduação),

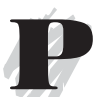

arafraseando GRAMSCI seria possível dizer, hoje, que o velho morreu, e o novo não nasceu ainda. Os desavisados e os incautos deverão, todavia, antes, saber de GRAMSCI (e de outros tantos), como há um preço pedagógico não só a ser pago para entender o novo tempo como, também, para tratar de não atrapalhar aos que, de boa vontade, querem fazer alguma coisa.

\section{HAYEK, FRIEDMAN, BUCHANAN} e outros ousaram - e conseguiram - estabelecer (ou tentar estabelecer) uma nova ordem; uma nova ordem - agora - mundial. É ela que responde aos novos tempos como ordem única, à qual aderem os vassalos de sempre (por pura ignorância) e os espertos de ocasião, pensando em tirar o melhor partido, não importando quem sejam os realmente derrotados: são os que descobriram - e se deslumbraram - com o chamado powershift, cunhado por TOFFLER. O difícil, mas difícil mesmo, é estar com a cabeça no lugar; e não aderir a nenhum dos dois lados porque, decididamente, não vão levar a nada; pelo menos se o que se pretende é democracia.

problema a ser enfrentado, então, diz respeito ao que IGNACIO RAMONET, diretor do Le Monde Deplomatique, chamou de o pensamento único. No mesmo sentido, já em 1995 falava sobre o assunto RICARDO PETRELLA, professor da Universidade Católica de Louvain, em texto com o título "As novas tábuas da lei". Ambos, porém - e aí está o núcleo da questão

1 Discurso de posse na Coordenação do Programa de Pós-graduação em Direito da Universidade Federal do Paraná, falando em nome, também, dos empossados na Vice-Coordenação do PPGD-UFPR (Professora Doutora ALDACY RACHID COUTINHO), na Coordenação do Curso de Graduação (Professora Doutora CARMEM LÚCIA SILVEIRA RAMOS), Vice-Coordenação do Curso de Graduação (Professor Doutor RICARDO MARCELO FONSECA) e Chefias e Suplências dos Departamentos de Direito Penal e Processual Penal (Professor Titular LUIZ ALBERTO MACHADO e Professor Doutor JOÃO GUALBERTO GARCEZ RAMOS), Direito Civil e Processual Civil (Professor MANOEL CAETANO FERREIRA FILHO e Professor Doutor EROULTHS CORTIANO JÚNIOR), Direito Público (Professor Doutor ROMEU FELIPE BACELLAR e Professora Doutora ANGELA CASSIA COSTALDELLO) e de Direito Privado (Professora Doutora MARCIA CARLA RIBEIRO e Professor EDSON ISFER). Salão nobre da Faculdade de Direito/UFPR, aos 13.11.2000. 
- partem do axioma de PAUL WATZLAWICK: "De todas as ilusões, a mais perigosa consiste em pensar que não existe senão uma realidade."

Sobreviver, assim, não está propriamente em aderir - ou não - ao comando central (e naturalmente produtor de exclusão, sobremaneira social), partido do Grande Irmão (no melhor estilo ORWELL) ou da mão invisível, de ADAM SMITH. O grande feito está em saber conviver com o mal, da mesma forma que se faz com a falta, na cura proposta pela psicanálise. Em ultima ratio, resistir é a palavra central; mas é preciso resistir sabiamente, inclusive para exigir o respeito pela diferença, razão por que há de ser feito por dentro, na convivência diuturna com as entranhas da nova ordem que, como disse JOAQUÍN ESTEFANÍA, oferece-nos um capitalismo de cassino, no qual todos jogamos sem o saber e no qual se joga conosco sem que o mereçamos. $\bigcirc$ grande dilema, destarte, é que quando se emite qualquer crítica ao sistema salta fora a fórmula Tina, ou seja, There is no alternative!, com o que se forja o cimento ideológico que une as elites mundiais de hoje (ESTEFANÍA), não fosse a célebre cooptação, através do que GALBRAITH chamou de poder condicionado: como o novo Deus não tem nação, haver-se-ia de quebrar as fronteiras dos países, a fim de que se produzisse a globalização. $\bigcirc$ rompimento das fronteiras possibilitou muita coisa boa (e daí não ter mais retorno, em parte, para o que é só pensar na Internet), mas, quanto às classes sociais, fez emergir uma estrada de duas mãos, isto é, levou o primeiro mundo para dentro do terceiro mundo e este para dentro daquele, de modo a, pelas benesses, engajar as elites periféricas de uma forma até então inimaginável, ou seja, cooptadas, assumem o discurso do senhor de modo radical, como os alemães fizeram-no após o trabalho genial (para o mal, naturalmente, como sucede aqui) de GOEBBELS. Esquecem, tão-só, é que, se houver guerra pela frente - e portanto, há que ter cuidado não vai ficar tijolo sobre tijolo; e isso não será na terra alheia.

Chegou a hora, enfim (embora já o façamos atrasados), de entrar no discurso e trabalhar dentro dele, embora contra ele porque ou se faz desde esse lugar ou nada se vai conseguir. Ensinar o Direito, por exemplo, seja ele qual for, dentro da velha ótica, é, sem dúvida, fazer o jogo esperado pelo novo Deus, porque à toda evidência, é transmitir uma falsa realidade, ou seja, é operar dentro e a favor da ideologia dominante, como tentou - até certo ponto de modo inútil - apontar MARX, por não lhe darem ouvidos. Não é isso, com certeza, que queremos para os nossos alunos. Sem embargo, por um outro lado, para os que seguem fazendo o jogo torto do novo Deus (e eis aí um fundamentalismo religioso com o deus mercado e sua doutrina calcada em uma única verdade e no pensamento único, portanto), não sobra outra alternativa que acordar para uma nova realidade e, se necessário for, derrubar bibliotecas. Em suma, a nação, por aquilo que tem de mais fértil intelectualmente, não pode seguir no chamado sono dogmático, agora muito mais grave porque mais efetivo, mais divulgador da nova ordem e, por conseqüência, muito mais destruidor. Aos que não quiserem saber, resta 
uma saída ética, coisa ainda da velha ordem, que é despiciendo aqui discutir.

Como disse SAMI NAÏR: "Las luces del siglos XXI serán: racionalismo crítico, universalismo concreto, voluntad política, justicia social, reparto del trabajo, derechos humanos frente a la razón de Estado, emancipación de las mujeres, derechos de las minorías, participación política, pedagogía ciudadana, innovación intelectual, preservación de los derechos de medio ambiente. En torno a estos valores deben unirse todos aquellos que, ahítos de amargura y horrorizados del odio que nace de la la desesperanza, aceptan apostar por el futuro y por la dignidad fundamental del ser humano. Estos son los rasgos de una sociedad futura que el actual fascismo rampante hace más urgente que nunca." (NAÏR, Sami. "La mirada comprometido de Joaquín Estefanía”. Epílogo. ESTEFANÍA, Joaquín. Contra el pensamiento único. 2. ed. Madrid: Taurus, 1998, p. 344). Assim, nada mais resta-nos que resistir conscientemente, operando por dentro do sistema e, se for o caso, contra os seus sicários, conscientes ou não.

Vale um mero exemplo, para que se registre e dê o crédito devido. Se a ordem é competição de mercado (que não tem e nunca teve ética alguma mas que, se agora adquiriu, por certo que foi aquela do bando de ladrões do qual falava GERMÁN GUTIERREZ) e se o que restou do Estado deve ser direcionado aos que têm menos condições, só resta uma conclusão (advinda do interior do novo Deus), em se pensando em termos de Universidade Pública: há ela que ser aberta para que todos os que preen- cham as condições mínimas possam entrar. Por certo ser necessário pensar mais na hipótese, mas nada seria impossível, inclusive começar pela Faculdade de Direito. Magnífico Reitor, dê-nos 10 (dez) professores assistentes a cada um e daremos aulas a todos os que não tiverem condições de pagarem as excelentes Faculdades particulares que se criaram diante de nossas barbas. Eis aí, então, um bom exemplo de competição de mercado onde, com as armas deles, plasmamos uma realidade com a qual não podem competir. Ora, veja-se bem, da mesma forma que se lê em FRIEDMAN (mas poderia ser HAYEK), que todos somos livres para morar embaixo da ponte (com um cinismo que já não espanta ninguém, pela banalização do cotidiano e dos valores), é possível dizer que todos são livres para estudar em qualquer Faculdade de Direito, abertas ao Deus dará como bazares, só que, não raro, para vender quinquilharias jurídicas. Assim, seria simples: quem quisesse fazer uma Faculdade de Direito excelente, procuraria, por ser-lhe de direito, uma Faculdade privada de excelência; e nós, nas desmontadas Faculdades públicas, com um pouquinho só de jeito e sem muita preocupação com a qualidade, que é o mal do qual nos acusam com indevida freqüência, justo porque, como se sabe, isso era coisa do tempo de SAN TIAGO DANTAS e de outros valores, ou seja, de opções políticas claras, onde o numerus clausus estava definido como opção visível pela qualidade (que se não abria mão), pagando-se o preço pela educação da intelectualidade nacional, fosse de que classe social fosse, senão por nada porque era como segue sendo - vital à construção do 
futuro da nação. Agora, porém, quando o senhor DI GENIO abre a Faculdade de Direito que quer, na hora que quer, instalando 20 (vinte) turmas, cada uma com 150 (cento e cinqüenta) alunos, como fez em Campinas, nada mais daquele velho discurso tem sentido. Qualidade de quem? Qualidade para quem? Ora, isso não importa em uma ordem onde a ética não diz nada. Vale - isso sim vale muito! - o lucro que cada aluno, feito cliente ou consumidor, dará, pagando por uma mercadoria que, de antemão, sabe-se podre, em grande parte das novas Escolas de Leis. E o pior não é isso. O pior é que não temos como combater algo do gênero (There is no alternative!), pelo menos se pensar com a lógica que impôs tal estado de coisas.

Para não sermos deliberadamente mal-entendidos, seria pertinente observar o teor de carta enviada, em 14.10.2000, ao Professor Doutor FERNANDO FACURY SCAFF, da Universidade Federal do Pará, hoje presidente da CEED-SESU, do MEC, encarregada do sistema de avaliação dos Cursos de Direito espalhados pelo Brasil:

"Acabamos de chegar de La Paz onde fomos falar no IX Encuentro Internacional de Derecho de America del Sur e encontramos sua mensagem (leia-se: Comissão de Especialista em Direito) e a da Professora LÉCIA MÁRCIA CAIXETA VIANA sobre a Comissão. Discutimos sobre a possibilidade e conveniência de ficarmos vinculado ao Cadastro de Consultores ad hoc da CEED. SESU (até porque não sabemos se a carta veio para um ou para o outro, certo?), embora preenchendo os requisitos - enfim! estabelecidos, ou seja, somos doutores (e já somos mestres também!) e nunca passamos perto de qualquer consultoria na área do ensino jurídico nos últimos dois anos. (...) Queremos dizer-lhe, todavia, que nossa decisão de prosseguir deve-se, exclusivamente, ao fato de você ser o Presidente da dita Comissão, por um monte de motivos mas, principalmente, porque é, antes de tudo, um homem sério e honrado, daqueles que não precisa do lugar e, se necessário for, chutará o balde, porque, ao contrário dos sedentos de Poder (BSB está repleta delles, a começar pela cadeira maior), não é isso que lhe dará camisa ou comida para os três filhos, certo? Então, há algo mais no Reino da Dinamarca que a podridão do desejo de poder; e a nossa esperança continua viva, embora saibamos que não é fácil. De qualquer forma, é preciso que a gente do Reino saiba - e você poderia dizer claramente isso a ela, agora tendo toda moral do mundo que tem gente que preza outros valores e vive no - e o-Brasil, ou seja, que vai estar aí cadastrado mas não precisa, por nada, disso, de modo a que entendam que os cadastrados (é um nome muito feio, não?) não são empregados (servidores seria melhor pela nova lei do Reino) do MEC, de qualquer de seus órgãos e, muito menos, do staff (não é SCAFF) da burocracia, tudo para evitar que comecem, mais uma vez, a pensar que temos ordens a cumprir (como já aconteceu antes), onde o diálogo de alguns tentou ser de patrão para serviçal, logo ajustado seja por alguma cabeça mais arejada, seja pelo repto necessário. Assim, ficamos na ad hoc, por você e para manter viva a esperança de que não consigam destruir tudo, o que não é empresa fácil. De qualquer maneira, ficamos felizes por você, mesmo 
porque sabíamos da sua indicação antes do telefonema ir a Belém, com todo o nosso apoio. Mas veja bem, caro amigo, BRASÍLIA É LONGE DEMAIS DO BRASIL; e quem não acordar para isso é engolido pela sua deslumbroca (gostou de neologismo?: deslumbramento candango (de alguns) com pororoca paraense!), ou seja, cooptado, pela sedução do desejo aquele, tudo de modo a fazer o discurso do status quo. (...) Ademais, é preciso ter presente que, para boa parte do Brasil, ir ou não ir (a um Seminário, em Florianópolis, na semana seguinte e sobre ensino jurídico, para o qual tão-só naquele momento estavam convocando a todos) pouco importa, porque há - e sempre houve - um deslocamento do eixo do poder e a gente do Reino continua achando que os do Brasil ainda não viram, mas estão enganados, viu? Mas é aí que reside o perigo, ou seja, o discurso da velha dinastia era bom, porque sério e bem intencionado: qualidade! Não se poderia esperar outra coisa de gente como PAULO NETTO, JOSÉ GERALDO e poucos mais. Mas depois de quase dez anos, as coisas mudaram: como sói acontecer, eLLes pegaram o discurso (nosso, ou melhor, que já vinha desde SAN TIAGO DANTAS e (...)) e passaram a usá-lo em benefício próprio. Se seguir assim, caro SCAFF, o trem descarrila, por muitos motivos, alguns facilmente perceptíveis: 1 . Com todo o rigor, as Faculdades maquiladas passaram brincando e, quando se disse não, o CNE-MEC (pelas reais forças do Poder; pelas mãos invisíveis), deram o ok, em verdade $\mathrm{KO}$ para nós; 2. Fizemos um monte de avaliações e foram, na medida do possível, produtivas, embora com um mundo de defeitos, inclu- sive pela precariedade de tudo (nós inclusive), razão por que nada, absolutamente nada, até agora, foi feito que pudesse mudar o modo de agir das arapucas (ao contrário, criaram-se outras!, com o aval do Reino), que continuam dando as aulas do mesmo jeito, pagando os mesmos salários, usando as bibliotecas alugadas (que vão percorrendo o Brasil - será que eLLes sabem ou fazem de conta que não? - como o caminhão da FUNDEP [é né?, aquele do qual levaram um montão?] distribuindo cultura), e um monte de outros abacaxis que se sabe não serão resolvidos; mas a arrecadação continua fantástica!; só que agora legitimada pela séria avaliação feita pelo MEC. Sentimo-nos uns imbecis (e não somos, querido e educado amigo?) quando escutamos isso de quem está com a burra cheia e os pobres alunos vazios da cultura jurídica que deveriam ter e receber. Ora, cansamos do falso discurso da qualidade, não por ele mesmo, que é perfeito e deveria prevalecer; mas porque, agora, como é visível, só tem servido para legitimar um monte de bandalheiras dos capitalistas do ensino do direito e seus SAVANAROLAS (íamos dizer GOEBBELS, mas nossa gente não tem tal cacife porque nos falta volksgeist), razão por que, humildemente, achamos ser tempo de mudar. Mas aí é que vem o problema, pelo menos para ver-se quem é quem na ordem do dia, ou seja, de que lado cada um quer mesmo jogar. A coisa é simples: dê dez assistentes para cada professor titulado das PÚBLICAS e DEIXE LIVRE O ACESSO, sem vestibular. Como somos ruins mesmo, todos vão querer ficar de fora, não? Pois há que dizer a eLLes: vocês ganharam!, agora não precisamos mais sequer fazer vestibular 
porque todos sabem que é melhor estudar na Privada. Assim, poderemos, de verdade, entrar no mercado competitivo, ou seja, pensando no povo (no melhor estilo gramsciano na base do ensino superior italiano), o qual continuará financiando o estudo daqueles que querem estudar e não têm condições de pagar mundos e fundos nas grandes e produtivas escolas privadas; ademais, como é livre a concorrência, quem quiser estudar nestas pode ficar tranqüilo que não haverá qualquer óbice da parte de ninguém. Ora, afora a brincadeira nossa aí contida, é preciso perceber que isso nunca aconteceu no Brasil porque a preocupação era a QUALIDADE, não é? Pois agora, quando a QUALIDADE já não preocupa mais (não nos venham dizer que ela está presente com quinhentos Cursos funcionando e tudo dos últimos anos, certo?), podemos também produzir em massa e, da QUANTIDADE (como fazem os alemães, italianos, etc.) sairá a QUALIDADE, o que parece óbvio. A diferença é que, agora, não se poderá dizer que funcionamos para preparar os filhos das elites (o que é uma farsa, mas é dito!), porque certamente eles preferirão deixar de disputar o bife nas Públicas para ter um ensino de excelência nas privadas. Ademais, a eles interessa a qualidade; e é aí que ela está, pois. Basta só escolher bem! Só um exemplo, para você ver como vão as coisas: fui (JACINTO) fazer uma conferência, ano passado, em Campinas, na PUC, na semana comemorativa deles, que já são quase cinqüenta. Ali, soube, aterrorizado, que o senhor DI GENIO não só criou ('ele faz isso na hora que quer!', disse-me um aluno da PUC) um novo Curso de Direito em Campinas como, também, na pri- meira fornada mandou ver com 20 (vinte) turmas e cada uma com 150 (cento e cinqüenta) alunos. Deu para entender bem? Está sentindo o que eu senti? Fez alguns pequenos cálculos? Viu o que é QUALIDADE? Viu quem é o pateta na história? Viu por que BSB é muito longe do Brasil? Viu onde é o Brasil? Mas não pára por aí: disseram-me (não sei se é verdade!) que custa algo em torno de $\mathrm{R} \$ 550,00$ (quinhentos e cinqüenta reais) por mês. Pois bem: fez cálculos de novo? Está entendendo o que estamos dizendo? Está percebendo que o discurso da QUALIDADE só tem legitimado isso aí? Ora, para um discurso neoliberal (e eLLes que não pensem que somos ignorantes nisso!), nada melhor que uma proposta neoliberal, na veia! Repetimos: se queremos o povo na Universidade -e que comece pelo Direito! - acabemos com o vestibular nas Públicas. No começo será uma tragédia mas, caídas as máscaras, tudo poderá andar melhor. Afinal, dar aulas para 150 ou para 1500 não faz muita diferença, a não ser que será necessário um microfone (darão \$ para tanto, não?), algumas salas maiores (embora não sempre porque a freqüência não seria obrigatória, para não continuar sendo hipócrita e ter que dar diploma também para o motorista do ônibus que sai do interior do Paraná e leva a tchurma, no final de semana e uma vez por mês, para o interior de São Paulo fazer de conta que estuda), uns dez assistentes para ajudar a atender os alunos e fazer as provas (orais, todas!), assim como cada um terá que escrever um Manual, um Handbuch (ou adotar um-ou uns - que preste), a fim de terem os alunos onde estudar, com a diferença que o professor terá que saber - também - o 
que nele está escrito porque, do contrário, a trem (...) Ora, não será - ou seria - muito complicado. O problema, mesmo, é saber quantos de nós estariam dispostos a pagar o preço, ou seja, parar de brincar com a democracia no ensino (pelo menos do Direito) e partir para algo que, no mesmo diapasão deLLes pudesse responder - quiçá uma vezaos interesses do nosso povo. Caro SCAFF, de tanto estudar essa coisa neoliberal estamos começando a pensar com a cabeça deLLes, tão-só com uma diferença: na nossa competição, o interessado é um indivíduo/consumidor coletivo chamado povo, que ainda não conseguiram matar (ou excluir?) e que insiste, pela nossa boca, que não é a da verdade nem tem qualquer pretensão de o ser, em seguir resistindo, embora, para nós mesmos, saibamos que há lugar no Olimpo do consumo e da inclusão (ninguém viaja pela Internet, roda de carro importado, viaja para o exterior às próprias custas, etc, sem estar aí, dando-se ao direito de sentir-se como sendo do primeiro mundo, como de fato o é, porque os neoliberais ofereceram-nos, às elites do terceiro mundo, uma estrada de duas mãos, como forma de cooptação e muitos aceitaram, renegando sua gente, em nome do status, qual a gente do Reino), em que pese manter-se a ética (inexplicavelmente, diriam eLLes: 'como foram escapar? onde foi que erramos? por que essas pecore nere? o que HAYEK e FRIEDMAN não pensaram? como pode essa gente continuar sustentando a diferença quando tudo, no global, é único, a começar pelo discurso? e così via $\left.(. . .)^{\prime}\right)$, mas, apesar de tudo, segue sendo melhor acreditar no sonho; no sonho de que ganhando todos podemos ganhar muito mais. Mas a parada não é fácil: cada um quer defender o seu, nem que seja um cacifezinho. Aí, é preciso RAZÃO (poderíamos dizer cidadania?), exatamente porque o problema está quando, como queria ROUSSEAU, o sujeito coloca a cerca em volta do lote (nem que seja na Vila candanga do Reino) e, seguindo a tradição diz: é meu! Infeliz egoísta que, pelo seu narcisismo, vende a alma ao diavoLLo. ETIENNE DE LA BOÉTIE tinha razão: obedecemos a vontade de um porque queremos ser que nem ele, ou seja, tiranos. Rei morto, rei posto: e viva o Rei! Bastaria, contudo, como diz o próprio LA BOÉTIE, não dar o que ele quer para a casa vir abaixo, ou seja, não dar a eLLe nossa razão (que é só imagens) e nossa liberdade, isto é, nosso desejo de posse e poder. Mas isso é possível? Sem saber muita coisa sobre o inconsciente, não podemos dizer, mas seguimos com a fé de que ino pasarán!; nem seguirão usando-nos como bonecos de ventríloquos, mormente para ficar mostrando a cara no lugar deLLes. Caro amigo SCAFF, você não precisa deLLes e, ao contrário do que podem pensar alguns, não está aí para fazer o jogo do faz-de-conta onde, falando em defesa de uns, fortalecemos a muralha dos castelos de outros. É di genio o poder; e só nos prestamos a seguir no jogo como está porque você é quem é. Ah! só mais uma coisa: tem gente que está no Programa do Seminário de Florianópolis e, contra suas recomendações (leia-se, da Comissão), fez consultoria: ou você não sabia? Viu, BSB é longe demais do Brasil (...)".

Quanto à Pós-graduação em Direito da UFPR, faz-se mister seguir o sendeiro da 
recuperação iniciada pelo Professor Doutor LUIZ EDSON FACHIN e seguida pelo Professor Doutor LUIZ ALBERTO MA$\mathrm{CHADO}$, com todo o conjunto de professores, alunos e servidores, não raro contra tudo e contra todos.

Vai daí termos duas grandes metas, sempre dentro das nossas possibilidades: primeira, subir mais ainda na avaliação da CAPES, porque já fazemos por merecer. Mas isso só se consegue com qualidade, razão por que se não duvide que com a massificação das Pós-graduações pelo país não há outra alternativa à avaliação que partir para a qualidade; e isso atingirá a todos, inclusive para manter o valor que têm os títulos adquiridos com grandes sacrifícios. Será necessário, portanto, sempre e sempre, uma melhor orientação (à qual todos os senhores professores estão convocados) e um melhor desempenho nas pesquisas e elaboração de teses e dissertações. Segunda, consolidar o PPGD-UFPR com a implantação de dois novos projetos já aprovados: $1^{\circ}$ ) uma nova área de concentração em Direito Cooperativo e Cidadania, a fim de que possamos começar um maior e imprescindível diálogo com os grandes mestres da própria UFPR, fazendo frente ao isolamento das faculda-

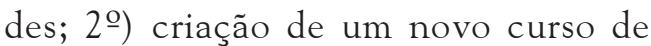
mestrado, em Direitos Humanos e Desenvolvimento, de modo a que, em cumprindo as diretrizes da CAPES, possamos realmente internacionalizar o Programa. Já aprovado o curso e firmado convênio com a Universidad Pablo de Olavide, de Sevilla, Espanha, esperamos construir um espaço onde, por certo, não seremos meros receptores, mas edificadores de um saber hoje já reconhecido mundo afora. Importante, todavia, é estarmos atentos à endogenia, tudo de modo a manter viva a imprescindível humildade.

No que toca com os senhores alunos, faz-se mister a consciência de que temos um Programa em uma Universidade Pública; e, mais, quem paga, no final de tudo, a conta. Assim, o desempenho de cada um há de ser primoroso e isso é o mínimo que se pode esperar. Em especial, referimo-nos aos senhores bolsistas que, além do mais, recebem para aqui estar. $O$ desempenho da grande maioria deles, em verdade, desde um ângulo da solidariedade, tem-se mostrado pífio, o que não é correto, nem justo. Preferimos devolver bolsas (se se fizer necessário, naturalmente) a manter tal estado de coisas. Destarte, vamos já organizar uma escala de atividades a fim de podermos contar mais de perto com os senhores bolsistas, tornando vivo nosso escopo de crescer pelas mãos de uma ação coletiva.

At last but not at least, não temos por que mudar a estrutura administrativa, que se mostrou vitoriosa, embora ainda deficiente de pessoal e instrumentos. Já rogamos às caras servidoras que, na relação com todos e, em especial, com os senhores alunos, façam tudo para manter a gentileza, quiçá uma estrada profícua ao bom relacionamento mas, que não tenham dúvida em endurecer qualquer contato onde não sejam bem tratadas. Afinal, é preciso não confundir gentileza com subserviência e, cada um do seu lugar, que trate de fazer sua parte. No final das contas, não teremos (como nunca tivemos) o receio de decidir o que for necessário. 
Gostaríamos, por derradeiro, de deixar claro que não dissentimos de SEABRA FAGUNDES quando dizia que "administrar é aplicar a lei de ofício". Por evidente, isso não é tudo; mas é um grande balizador a quem administra e aos homens de bem. Como dizia com toda a propriedade o Professor Doutor EGAS DIRCEU MONIZ DE ARAGÃO - e Professor Doutor LUIZ ALBERTO MACHADO repete sempre "amigo da gente é quem não nos causa problemas". Pedir, portanto, a quem administra, o impossível, é causar-lhe um problema e, de regra, é preciso desconfiar da amizade. Quem tem razão - é preciso que se diga em alto e bom som - merece guarida sempre, seja lá quem for (só um ingênuo poderia pensar o contrário conhecendo-nos como conhecem); quem não a tiver, por favor, seja amigo.

Temos esperança; e a temos porque acreditamos na imensa capacidade deste grupo. Com ele, construiremos um futuro melhor, com "vida em abundância para todos". (JOÃO 10,10). Afinal, continua de pé a lição da nossa poetisa-maior, HELENA KOLODY:

"Para quem viaja ao encontro do sol, é sempre madrugada." 